DOCTRINA

\title{
La participación ciudadana en el combate contra la corrupción: Un análisis desde la carga de prevenir el daño en el panorama jurídico colombiano
}

\author{
Citizen participation in the fight against corruption: An analysis from \\ the preventing the damage in the Colombian juridical overview
}

\section{William Iván GALLo Aponte \\ Universidad Externado de Colombia}

\begin{abstract}
RESUMEN El fenómeno de la corrupción penetra en lo más profundo de la conciencia de los pueblos, obstruyendo la estabilidad de las instituciones, el desarrollo económico y el progreso social. Por esta razón, es una preocupación latente desde diferentes latitudes, y particularmente en Colombia. En este sentido, la actuación de los agentes públicos para contrarrestarla no es suficiente, por lo que se ve la necesidad de una activa participación e intervención ciudadana, que, además, constituye uno de los pilares del Derecho Administrativo contemporáneo. De esta manera, a través de un análisis de la carga de prevenir o mitigar el daño antijurídico, tanto en el derecho privado como en la contratación estatal, y con una presentación de los diferentes escenarios, instrumentos y garantías a través de los cuales se desarrolla la participación ciudadana, se propone y justifica el empoderamiento de la población civil en el desarrollo de las actividades públicas para combatir la corrupción.
\end{abstract}

PALABRAS CLAVE Corrupción, prevención, daño, participación ciudadana, contratación pública.

ABSTRACT The corruption penetrates in the deepest roots of people's consciences, obstructing the stability of the institutions, and both the social and economic development. Therefore, this issue is a concern in different places, and particularly in Colombia. Hence, the acts of the public agents are not enough to tackle the problem because there is a need for a more active participation and intervention of the citizenship, which also constitutes one of the pillars of the contemporary Administrative Law. Through an analysis of the prevention or mitigation of the anti-juridical damage, both in private law and state contracting, and with a presentation of the different scenarios, instruments and guarantees through which citizen participation is developed, the empowerment of 
the civilian population in the development of public activities to combat corruption is proposed and justified.

KEYWORDS Corruption, prevention, damage, community participating, public contract law.

\section{Introducción}

«La corrupción es una plaga insidiosa que tiene un amplio espectro de consecuencias corrosivas para la sociedad». Bajo esta premisa se da preámbulo a la Convención de las Naciones Unidas contra la Corrupción; y no es para menos, puesto que existe una preocupación latente entre las naciones por exterminar este mal, aquel «absceso canceroso» (Esner, 2000: 41-56) que penetra en lo más profundo de la conciencia de los pueblos y obstruye las arterias de la estabilidad institucional, el desarrollo económico y el progreso social.

La profundidad de su origen y la anegable extensión de sus efectos representa el uso de un poder déspota y corrosivo, que desvía el cauce de lo correcto hacia un mar de incertidumbre, donde se oculta el interés público como finalidad del Estado (Wunder, 2011: 162-163) y da paso a la ambición como insignia del particular.

La realidad es preocupante, pues según las estadísticas, la corrupción es el principal problema de Colombia en este momento (Boletín número 18.178 de la Fiscalía General de la Nación de Colombia, 2017), y sin dudarlo también lo es en gran parte de América Latina. Los casos pululan, es así como van desde la entrega de sobornos cuantiosos para obtener la adjudicación de diferentes tramos relacionados con importantes vías del país por parte de la compañía Odebrecht, acreditados por la Fiscalía General de la Nación en colaboración de la comunidad internacional, hasta los hallazgos en el departamento de la Guajira, donde se concluyó que hubo corrupción por parte de las instituciones privadas y públicas que se llevaron el dinero destinado a la alimentación de los niños. ${ }^{1}$

Ante esta nefasta y preocupante realidad de la que «ningún país es inmune» (Secretaría de la Transparencia de la Presidencia de la República de Colombia: 2013), la sociedad se enfrenta a evaluar no solo el papel de las instituciones públicas en el combate contra la corrupción, que sin duda es el más determinante, sino también el de todos los ciudadanos del común, que de alguna u otra manera nos vemos perjudicados por todos los efectos que genera.

Y no es para menos, su necesidad es notable; frente a la golpeada institucionalidad de los Estados que conlleva a la inadecuada proyección y ejecución de las políticas y

1. «En la Guajira se perdieron más de 16.000 millones para alimentación escolar». Informe de la Revista Semana del 25 de julio de 2016. 
programas sociales, económicos y culturales, debemos convertirnos en participantes activos de la lucha contra la corrupción.

De esta manera, se ve necesario el fortalecimiento al papel que juega la sociedad civil. A manera de ejemplo, un papel fiscalizador de la ciudadanía para garantizar la transparencia de las acciones estatales (García y Revelo, 2010). Si bien dicho «control social» no es novedoso, la actualidad y transformación que enfrenta resultan necesarias de analizar para verificar su efectividad y actualidad.

En ese sentido, el problema jurídico central que pretende desarrollar este escrito consiste en determinar que, si en la celebración de contratos el Estado es el representante de los intereses de los ciudadanos, éstos a su vez ¿tienen la carga de evitar o mitigar el daño derivado de la corrupción? Puesto que, sin dudarlo, son los más perjudicados.

Metodológicamente el presente escrito se estructura bajo los siguientes puntos. En primer lugar, se realizará un análisis sobre la prevención del daño antijurídico como herramienta de combate contra la corrupción, dentro del cual se determinan los presupuestos ius privatistas de la representación en sede administrativa. Asimismo, se evaluará la posibilidad de atribuirle a los ciudadanos la prevención o mitigación del daño antijurídico, y si ésta constituye una carga o una obligación. En aras de lograr este cometido, se ahondará sobre los fundamentos clásicos, las características y la titularidad de la figura.

En segundo lugar, se estudiará el papel de la participación ciudadana en el derecho administrativo contemporáneo como una herramienta para la construcción de la transparencia. Ahí se pretende mostrar las diferentes formas a través de las cuales los ciudadanos intervienen en los procesos de contratación pública, así como los instrumentos, su utilidad y las garantías que brinda el ordenamiento jurídico para lograr con «éxito» su cometido, en aras de que se generen resultados adecuados. Por último, se presentarán unas consideraciones finales con relación a todo lo desarrollado en los diferentes puntos.

\section{La prevención del daño como herramienta de combate contra la corrupción}

Prevención del daño: Análisis de los presupuestos ius privatistas

de la representación en sede administrativa

La mejor aproximación que se le puede brindar a la prevención del daño desde el derecho administrativo, en interés de lograr su entendimiento, toma como referencia la teoría general del negocio jurídico; no porque se trate de una figura exclusiva en la responsabilidad contractual, puesto que también se extiende en materia extracontractual (San Martín, 2012: 17-35), sino porque concretamente, a partir de la representación, se relacionan de manera armónica los elementos de poder, actos jurídicos, legitimación y sujetos representados, etcétera. 
De esta manera, invocar desde esa arista los componentes de la representación supone adecuarlos a unos principios constitucionales y legales que fijen los límites de los conceptos y la adecuación de las disposiciones, con un objetivo concreto: el cumplimiento de los fines del Estado (artículo 2 de la Constitución Política de Colombia, 1991).

Sin embargo, cabe advertir que el uso de la «representación», para efectos de este escrito, no pretende dar lugar sobre su adecuación en términos políticos o parlamentarios, sino más bien una referencia general desde el plano eminentemente jurídico. Es más, concretamente, cuando el Estado a través de las entidades de cualquier orden celebra contratos para el cumplimiento adecuado de sus fines.

Por tanto, si se toma como premisa una figura del ámbito contractual, partir de un concepto de Estado en los mismos términos deviene útil para lograr un paralelismo adecuado. Así, Hobbes, en su obra El leviatán, lo define como

una persona de cuyos actos una gran multitud, por pactos mutuos, realizados entre sí, ha sido instituida por cada uno como autor, al objeto de que pueda utilizar la fortaleza y medios de todos, como lo juzgue oportuno, para asegurar la paz y defensa común (Hobbes, 1987: 141).

Ciertamente, un concepto hobbesiano de Estado se estructura en términos de defensa y seguridad. Sin embargo, tras estos elementos de poder, debe entenderse que reaparecen «las [...] ideas esenciales de sociedad y de bien público» (Dabin, 2003: 79).

Por otro lado, también podría entenderse el Estado ya no en los términos propuestos, sino más bien bajo la idea de contrato social en un nivel más abstracto, como lo propone Rawls, es decir, tras la elección hipotética de los principios de justicia, que han de ser satisfechos por una institución social, que tiene comprometidos, cooperando mutuamente, que consienten en que son libres e iguales (Rawls, 2006: 18-21).

En una y en otra perspectiva se deriva una visión «contractualista» de Estado que daría pasos agigantados a una gobernabilidad cooperativa, donde la acción pública se convierte en el producto de interacciones entre protagonistas múltiples, públicos y privados, que invita a los ciudadanos a participar en la definición de las normas a las cuales se les somete a través de un diálogo permanente entre gobernantes y gobernados (Chevallier, 2011: 237-250).

Bajo esto, se entendería que los ciudadanos autorizan y transfieren al Estado (persona jurídica; artículo 80 de la Ley de Colombia 153 de 1887) su derecho de gobernarse a sí mismo, confiriéndole todo su poder (entendido en términos del derecho privado), reduciendo sus voluntades a una sola voluntad, en la medida en que el mismo actuará como representante de su persona y su personalidad.

Con la confianza de entender al Estado en los términos propuestos, hablar de representación supone una «necesidad ineludible» (Hinestrosa, 2008: 77-82), pues «campea en todos los aspectos de la vida social [...]. Es un juristisches Wunder (milagro jurídico), solo que no únicamente jurídico, y menos apenas en el ámbito del 
derecho privado, sino también un milagro económico y, mucho más, uno político: baste pensar en la formación del Estado moderno» (Hinestrosa, 2008: 112).

Así, se define la representación genéricamente como la «legitimación para obrar por cuenta ajena» (Bianca, 2007: 92). De ahí, adecuándolo al plano administrativo, tal representación ¿será directa o perfecta en tanto el Estado como representante tiene el deber de hacer presente que no obra para sí, sino por cuenta ajena, es decir, en nombre de los ciudadanos, y que esto resulte evidente del contexto de la actuación, manteniéndose dentro de los límites legales? (Hinestrosa, 2008: 133). O, más bien, ¿será indirecta o de intereses, en tanto el Estado, a pesar de obrar por cuenta ajena (a favor de los ciudadanos), "provisto de un poder [...] procede en nombre propio?» (Hinestrosa, 2008: 362).

En cierta medida es más adecuado aceptar que la gestión del Estado como representante se enmarca en una categoría indirecta, puesto que si no fuese así, estaríamos aceptando que, concretamente, en el marco de la contratación pública, éste no obra por cuenta propia. Es más, que lo precede una calidad de extraño que le permite una vez celebrado determinado negocio, desaparecer sin comprometerse (Hinestrosa, 2008: 141).

Contrario sensu, aceptar que el Estado actúa como representante indirecto o de intereses da a entender que procede en interés ajeno pero en nombre propio a través de las entidades que hacen parte del sector central o del sector descentralizado por servicios, en este caso, porque «lo dice» expresamente; $y$ es evidente, en tanto el Estado al celebrar contratos busca la efectividad de los derechos e intereses de los administrados (artículo 3 de la Ley de Colombia 80 de 1993), que a la postre es su finalidad.

Circunscribiendo la figura a lo aceptado, respecto del poder conferido al Estado, existe y tiene características propias; si no fuese así, actuaría como agente oficioso. Dicho de otro modo, el acto de apoderamiento fuente de la legitimación del Estado, a nuestro parecer, es un mandato constitucional, al disponer que: «las autoridades de la República están instituidas para proteger a todas las personas residentes en Colombia, en su vida, honra, bienes [...] y para asegurar el cumplimiento de los deberes sociales del Estado y de los particulares» (artículo 2 de la Constitución Política de Colombia, 1991).

Este acto de apoderamiento conferido al Estado también puede entenderse en términos de potestad, puesto que, «comprende un conjunto de poderes de carácter funcional [...] al servicio de los fines e intereses» de otros (Diéz-Picaso, 1979: 128). Asimismo, su fuente reposa en la ley, por cuanto constitucionalmente se le ha atribuido al Estado una función específica y necesaria: establecer determinadas situaciones que exigen una provisión de intereses, de alguien que por diferentes motivos no puede actuar por sí mismo (Hinestrosa, 2008: 199-202).

Dicho poder se caracteriza por ser general, en tanto que el Estado puede realizar cualquier acto jurídico en interés de sus administrados. Sin embargo, dicho «poder 
general no quiere decir atribuciones omnímodas [...] sino simplemente autorización para «efectuar actos de administración»» (Hinestrosa, 2015:574). Es así como la constitución «determina imperativamente la extensión y profundidad de las atribuciones del representante» (Hinestrosa, 2015: 571-572) al disponer en su artículo sexto que los servidores públicos son responsables por infringir la constitución y las leyes, así como por la omisión o extralimitación en el ejercicio de sus funciones.

El Estado como representante debe actuar con diligencia, cuidado, lealtad y transparencia para con sus representados o administrados. En caso de infringir estos deberes será responsable (artículo 90 de la Constitución Política de Colombia, 1991). Sin embargo, cabe preguntarse, $i$ si se declara su responsabilidad, pueden los ciudadanos revocar el poder? De manera evidente no, por cuanto le precede un mandato superior de rango constitucional. Supóngase, por ejemplo, si alguien ha renunciado a la nacionalidad, por esta razón, no se le impide el ejercicio y la garantía de sus derechos, salvo las disposiciones legales.

Asimismo, tiene otros deberes, entre ellos rendir cuentas de sus actuaciones (artículo 3 número 9 de la Ley de Colombia 1.437 de 2011), y la «custodia y protección de todos los bienes del dominus» (Hinestrosa, 2015: 575).

Sobre este último, es importante determinar si los bienes del Estado son los bienes de sus administrados. Ante tal cuestionamiento la doctrina ha determinado que si bien el dominio recae sobre el Estado, es decir, existe un verdadero derecho de propiedad, que es público, éste se encuentra sujeto a un fundamento constitucional finalista: el cumplimiento de los fines del Estado bajo los principios de la función administrativa (artículo 209 de la Constitución Política de Colombia, 1991), lo que lo hace un «derecho de propiedad sui generis de carácter constitucional» (Pimiento, 2015: 262).

Por la finalidad a la que están sujetas los bienes del Estado, se defiende la existencia de un deber de custodia y protección sobre los mismos. Además, respecto a la obligación de entregarle a los administrados lo recibido debido a su gestión (Hinestrosa, 2015: 574), se debe entender como la garantía en cabeza del Estado a favor de los derechos «realizados a través de los bienes de uso público» (Pimiento, 2015: 578).

Desde los administrados, el entendimiento de la «representación» ha indicado que en su condición de representados deben proveer al agente (Estado) los medios necesarios para el desempeño de su gestión (Hinestrosa, 2015: 578). Esto mismo, pero en otras palabras, lo consagra el artículo 95 de la Constitución Política de Colombia, al disponer que «son deberes de la persona y del ciudadano [...] contribuir al financiamiento de los gastos e inversiones del Estado».

Por otro lado, pero con relación a los administrados, no deben una retribución al trabajo del Estado, por cuanto su actuación es gratuita (Gordillo, 2014: 399).

Desde el punto de vista de la responsabilidad del representante, ya no para verificar la irrevocabilidad del poder, pues ya fue objeto de análisis en párrafos precedentes, sino para determinar el destino del producto de la relación, decimos que al proponer 
una representación indirecta, «los efectos del acto [...], no obstante que el agente obra por cuenta ajena, se radican exclusivamente en cabeza de él» (Hinestrosa, 2015: 603).

Por otro lado, la terminación de la representación legal desde el derecho privado procede «cuando cesa su razón de ser» (Hinestrosa, 2015: 636), ya que el representante no puede renunciar (Hinestrosa, 2008: 170). Contrario sensu, desde el derecho público, se entiende que por parte del Estado existirá una permanencia en la regulación y aplicación del ordenamiento jurídico, que genera una confianza legítima, propia de los principios constitucionales del Estado Social de Derecho (Bermúdez, 2005: 83).

En definitiva, bajo la advertencia de haber tomado la figura de la representación por su generalidad, puesto que esta supone una diversidad de particularidades y características, no por esto menos importantes, podemos concluir que la representación que recae sobre el Estado es constitucional, indirecta, otorgada bajo un poder general derivado del contrato social, materializado en la norma superior, sujeto de obligaciones cuya prestación está enmarcada en el cumplimiento de los fines del Estado.

\section{¿Carga u obligación de prevenir el daño? \\ Fundamentos, características y titularidad}

Cuando se hace referencia a la prevención del hecho dañino desde una perspectiva general, es necesario identificar los límites del iter damnum para determinar el momento a partir del cual cobra importancia. En ese sentido, el marco común de referencia está dado por la definición general de daño, entendida en términos apresurados como toda afrenta a los intereses lícitos de una persona, tratándose de derechos de cualquier índole, que se presenta como la alteración del goce pacífico o la lesión definitiva de los mismos (Henao, 2015: 278).

En vista de lo anterior, la prevención del daño cobra importancia hasta antes de la amenaza del mismo y no de su lesión definitiva. De esta manera, será necesario conocer qué tipo de conductas son potencialmente dañinas a efectos de, en un primer momento, evitarlas, o frente a la imposibilidad de esto, mitigar sus efectos. ${ }^{2}$

Los presupuestos hasta ahora mencionados son aceptados tanto por el derecho privado como por el derecho administrativo, pues constituyen un objetivo necesario en términos de seguridad, eficiencia, garantía y economía, etcétera. Por esta razón, será necesario determinar la utilidad de la prevención del daño cuando se trata de instituirla como herramienta de combate en la lucha contra la corrupción.

Sin embargo, antes de aproximarnos a los fundamentos teóricos de la prevención

2. Esta premisa contribuye a la configuración del deber o principio de no dañar, que, desde la antigüedad, con los romanos y los preceptos del derecho propuestos por Ulpiano, consistía en: vivir honestamente, no hacer daño a otro, atribuir a cada uno lo suyo. (D. 1.1.10.1. Iuris praecepta sunt haec: honeste vivere, alterum non laedere, suum cuique tribuere). 
del daño, será necesario establecer la posición de las partes, quienes ya sea por el contrato social o por los contratos que celebra el Estado con los particulares, han sido instituidas con el fin de atribuirle obligaciones y cargas para el adecuado cumplimiento de los fines.

Por esta razón, si por el contrato social los ciudadanos son partes, por los contratos que celebra el Estado con los particulares, son terceros relativos. Es decir, sin ser parte en el negocio y sin perder la condición de extraños, tienen una relación con una de las partes (el Estado) y pueden verse lesionados en sus propios derechos legítimos a consecuencia de dicho acto (Ospina y Ospina, 2014: 502), «y en esa virtud está legitimado para alegar la ineficacia de aquel» (Hinestrosa, 2015: 516).

A pesar de que los contratistas particulares también son ciudadanos que deben colaborar en el logro de los fines del Estado (artículo 3 inciso segundo de la Ley de Colombia 80 de 1993) en virtud de su relación directa derivada del contrato, serán tomados (a efectos prácticos del presente escrito) como parte en sentido sustancial, debido a que son estos los titulares del interés de obtener utilidades de contenido pecuniario y son los destinatarios directos de los efectos del negocio (Hinestrosa, 2015: 525).

En otras palabras, un contrato que celebre el Estado en cumplimiento de sus fines involucra tres sujetos jurídicos: El Estado y los contratistas particulares como partes y los ciudadanos como terceros relativos. De esta manera, frente a una situación de corrupción se genera un daño que en virtud de las consecuencias nefastas que produce, genera una carga al perjudicado: evitar o mitigar el daño.

Tomando como referencia lo anterior, en primer lugar, consideramos que esta forma de evitar un daño «no se trata de un deber en el sentido verdadero y propio de la palabra, sino de una "carga», es decir, de un acto que el perjudicado está llamado a ejecutar en su propio beneficio», ya que «en el deber, el sujeto cuyo interés se protege es un tercero», cuya característica «es la obligación de resarcimiento a que da origen su infracción, la cual no ocurre cuando se trata de evitar el daño» (San Martín, 2012: 313).

Entonces, consideramos que son los ciudadanos los perjudicados por los daños derivados de la corrupción, por cuanto a pesar de no ser parte, los efectos nefastos de ésta les afectan en virtud del principio de la relatividad de los contratos. Verbigracia, la corrupción trae como consecuencia una debilidad institucional en términos de confianza, eficiencia, presupuesto, etcétera, que permea todos los sectores económicos y sociales.

Concretamente, la carga de evitar o mitigar el daño producto de la corrupción es de los ciudadanos, por cuanto son los perjudicados por ésta. Y se justifica históricamente desde una visión ius privatista, en que dicho reconocimiento tenía fundamento en la culpa de la víctima o perjudicado, entendida como un «comportamiento reprochable de aquel a quien debían ser atribuidas las consecuencias de un determinado hecho propio, en razón de que, pudiendo hacerlo, no había mantenido un comportamiento 
acorde al modelo de conducta preestablecido», pues «debía ser cuidadoso, atento y escrupuloso, tanto en lo propio como en lo ajeno» (San Martín, 2012: 129-132).

Lo anterior fue el presupuesto del derecho antiguo, vigente aún para el derecho privado contemporáneo. ${ }^{3}$ Sin embargo, con la función social de la responsabilidad civil se ha perfeccionado su entendimiento mas no su atribución, en tanto que se pasó de un principio relacionado con la culpa, para que el individuo sienta la amenaza de un juicio de responsabilidad frente a su actuar negligente hacia un contenido económico en el análisis sobre costos e incentivos (Cortés, 2009: 63).

Además, podríamos extender tal entendimiento hasta el cumplimiento de una finalidad, en este caso la promoción de la prosperidad general y la garantía efectiva de los principios, derechos y deberes constitucionales, pues no en vano se ha dicho respecto a la tutela integral de la persona en el marco de la reparación de daños y respetando los límites propios del contenido de la responsabilidad civil: «la responsabilidad parece estar íntimamente ligada con los propósitos mismos del Estado» (Cortés, 2006: 178).

Asimismo, para la doctrina del derecho privado el daño evitable se incorpora como un aspecto de la «buena fe objetiva», o más bien de la «culpa de la víctima», o quizá en ambas, pero en últimas dependerá del área de responsabilidad civil en que se trabaje (San Martín, 2012: 30-33). Desde el derecho administrativo, con relación a los perjudicados, a nuestro juicio se incorpora desde la misma constitución.

Concretamente en el artículo 95, al consagrar que: son deberes (entiéndase cargas en algunos) «de la persona y el ciudadano: [... 3. Respetar y apoyar a las autoridades democráticas legítimamente constituidas para mantener la independencia y la integridad nacionales $[\ldots]$ 5. Participar en la vida política, cívica y comunitaria del país. 6 . Propender al logro y mantenimiento de la paz [...]».

En síntesis, si bien la carga de evitar el daño reposa sobre los ciudadanos por cuanto son los perjudicados por los actos de corrupción derivados de la indebida contratación pública, como fuente más evidente que lesiona sus intereses, a consecuencia que genera la inobservancia de dicha carga es de autorresponsabilidad, por cuanto no es susceptible de forzar su cumplimiento (San Martín, 2012: 323-327).

Sin embargo, a diferencia del derecho privado, tratándose de esta carga en cabeza de los ciudadanos, en el derecho administrativo, el Estado no puede «alegar que su obligación ha decaído o disminuyó por la inobservancia de la carga» (San Martín, 2012: 254) por la misma concepción finalista a la que está atada su actuación.

Lo dicho hasta acá en materia de prevención del daño supone una extensión de la concepción clásica, pero a la vez actual, de la carga del perjudicado de evitar o mitigar

3. Véase, por ejemplo, las aproximaciones más significativas en América Latina con Perú y Bolivia en lo que tiene que ver con el no resarcimiento del daño que el acreedor hubiera podido evitar empleando la diligencia ordinaria (San Martín, 2012: 242). 
el daño en el derecho privado, por cuanto en virtud del principio de relatividad de los contratos puede haber terceros relativos a quienes los efectos les interesa. En caso de ser perjudiciales, están llamados a evitar la generación del hecho dañino, pero, como no estamos ante una sociedad perfecta, frente a la imposibilidad de evitarlos, por distintas razones, entraría a tomar medidas en torno a su mitigar sus efectos nocivos.

Por otro lado (con el objetivo de seguir en la conclusión de este punto), la presentación de la carga de evitar o mitigar el daño respecto de los ciudadanos como perjudicados (De Cupis, 1970: 572-577), no desconoce la existencia de deberes y cargas propias de la relación contractual (Estado-contratistas).

Finalmente será necesario enfatizar que, frente a la posible producción de un acto de corrupción, los ciudadanos tienen cargas, puesto que se trata de velar por sus intereses sociales y su adecuada ejecución. Y frente a su inobservancia, no son sujetos de responsabilidad civil; quizá dependiendo del grado de proximidad y conocimiento con la fuente de corrupción sí lo serán en materia penal por favorecimiento o receptación (artículos 446 y 447 de la Ley de Colombia 599 de 2000), pero se tratará de una situación particular.

\section{La participación ciudadana en el derecho administrativo contemporáneo: una herramienta para la construcción de la transparencia}

La importancia de la participación ciudadana en la prevención de las consecuencias dañinas derivadas de los actos de corrupción se enmarca, como lo diría García de Enterría, en una «actuación cooperativa, en que el administrado, sin dejar de actuar como tal y sin cumplir funciones materialmente públicas, secunda con su actuación privada el interés general» (García de Enterría y Fernández Tomás-Ramón, 2005: 79).

Tal actuación corresponde a la materialización del principio democrático como uno de los pilares centrales en la formación del sistema de Derecho Administrativo (Abmann, 2014: 19-38), a través del cual la administración pública articula todos sus mecanismos para lograr la participación concreta de los ciudadanos en sus decisiones.

De esta manera,

en el derecho administrativo contemporáneo se ha reconocido la necesidad de reforzar la legitimación en general y la legitimación democrática de la administración pública en el sentido de que ya no basta la legitimación derivada del simple respeto de la legalidad [...] propia del Estado liberal de derecho, sino que es necesario que existan otras fuentes de legitimación de la actuación administrativa. Esta situación es el resultado de los diversos cambios en el quehacer de la administración pública, pero, especialmente, de la crisis de la democracia representativa y de la incorporación de la democracia participativa, junto con el fortalecimiento de los poderes de intervención y de decisión de la administración pública [...] (Santos, 2016: 448). 
Si bien es necesario brindar «oportunidad a los administrados de intervenir en el proceso de adopción de decisiones por las autoridades» (Santos, 2016: 490), también será un deber del Estado implementar medidas que procuren optimizar el desarrollo de las distintas formas de participación, las cuales se logran a través de la protección del pluralismo y la promoción de estructuras democráticas en las diferentes formas de organización social (Corte Constitucional de Colombia, sentencia C-150-2015).

La concreción de estos postulados obedece a la finalidad misma del Estado, cuyo ejercicio se evidencia desde el reconocimiento constitucional a la participación de diferentes organizaciones de consumidores (artículo 78 de la Constitución Política de Colombia) hasta la organización de las formas y sistemas de participación ciudadana que permitan vigilar la gestión pública (artículo 270 de la Constitución Política de Colombia). ${ }^{4}$

De esta manera, tratándose de la participación ciudadana como una herramienta para la construcción de la transparencia en el combate contra la corrupción, es una preocupación latente de los pueblos que tiene reconocimiento supranacional expreso.

En ese sentido, la Convención de las Naciones Unidas contra la Corrupción propone la participación de la sociedad como medida preventiva, a través de la incorporación por parte de los Estados de mecanismos para la promoción de la participación activa de personas y grupos que no pertenezcan al sector público. De forma concreta, aumentando la transparencia y el fomento en la contribución de la ciudadanía a los procesos de adopción de decisiones. Por otro lado, la Convención Interamericana contra la Corrupción, dentro de las medidas preventivas, propone la creación de mecanismos para estimular la participación de la sociedad civil, así como de instrumentos de protección a quienes denuncien actos de corrupción.

Asimismo, la Carta Iberoamericana de Participación Ciudadana en la Gestión Pública, en su capítulo cuarto, determina cuán preciso es asegurar la articulación de los mecanismos de participación ciudadana, en especial los del control, para la lucha contra la corrupción.

Pueden resultar bastantes e interesantes las diferentes iniciativas de organismos internacionales para cercenar la insidia que comporta la corrupción. Sin embargo, para efectos concretos, se analizarán los escenarios e instrumentos de participación ciudadana dispuestos por el ordenamiento jurídico colombiano en atención al tratamiento de esta enfermedad.

De acuerdo con lo anterior, cabe advertir que, pese a que «el control social de la administración» no es un asunto novedoso en el Estado Social de Derecho, la nece-

4. Cabe destacar que estas no son las únicas formas de participación que reconoce la Constitución colombiana. También encontramos el reconocimiento de comunidades ambientalistas (artículo 79), asimismo, la consagración constitucional de los mecanismos de participación del pueblo en ejercicio de su soberanía (artículo 103), etcétera. 
sidad de verificar su aplicación requiere mención especial para determinar su efectividad y actualidad. Verbigracia, se debe propugnar por estrategias prácticas y reales fuera de propuestas abstractas y generales que solo se convierten en un manual de «buenas intenciones», sin fundamentos claros y útiles. ${ }^{5}$

Ahora bien, concretamente en el ordenamiento jurídico colombiano, en el marco del "posconflicto», se ha desarrollado una alianza para el gobierno abierto que involucra desde la participación ciudadana en diferentes escenarios hasta la lucha contra la corrupción en el Estado (AGA, 2017).

De esta manera, resulta interesante verificar las diferentes formas y mecanismos con los que cuenta el Estado colombiano para la promoción de la participación ciudadana y de ahí el combate contra la corrupción, permitiendo verificar si realmente es una herramienta útil para lograr tal cometido.

\section{La intervención ciudadana en los contratos que celebra el Estado colombiano}

El proceso de contratación pública en el ordenamiento jurídico colombiano se establece dentro de ciertas etapas. En primer lugar, la etapa de planeación o pre-precontractual, la cual da inicio al proceso con la presentación del proyecto de pliego de condiciones. En segundo lugar, una etapa de selección o precontractual, marcada por la expedición del pliego de condiciones; por último, la etapa contractual, que determina la celebración, ejecución y liquidación del contrato.

Bajo este proceso, la ley determina que «las organizaciones de la sociedad civil y los ciudadanos cuando ejercen la participación ciudadana en los términos de la Constitución Política y de la ley» (artículo 2.2.1.1.1.2.1 del Decreto de Colombia 1.0822015) son partícipes del sistema de compras y contratación pública.

En ese contexto, el marco regulatorio de la contratación estatal en Colombia da prevalencia al interés público inherente a toda la gestión del Estado (Matallana, 2013: 82-84). ${ }^{6}$ De ahí, la comunidad tiene derecho a conocer quiénes, por qué y cómo se toman las decisiones (Dávila, 2016: 11) a lo largo del proceso y de esta manera lograr identificar, prever o mitigar los posibles efectos dañinos que generan aquellas, al tratarse de perjuicios en contra de la sociedad misma.

5. En ese sentido, el Ministerio Público de Colombia, mediante resolución 186 del 15 de mayo de 2015, adopta una política interna para el aprovechamiento de los mecanismos y espacios de participación ciudadana en el marco del fortalecimiento de una función preventiva. Manifestación que, a nuestro juicio, no aporta al objetivo por el cual se profiere, sino que se convierte en un conjunto de ideas generales sin «dientes» para actuar.

6. La prevalencia del interés público en la contratación pública colombiana se dispone, por ejemplo, desde la definición de la conveniencia o inconveniencia del objeto a contratar (número 7 del artículo 25 de la Ley 80); asimismo, al definir las reglas de participación en los pliegos de condiciones en la garantía de la selección de la oferta más favorable. 
La ejecución y consagración de dicha prevalencia se enmarca en el principio de transparencia, ${ }^{7}$ según el cual, grosso modo, los interesados de los procesos contractuales tendrán oportunidad de conocer y controvertir las diferentes actuaciones públicas. Asimismo, propugna por la debida ejecución de los requisitos objetivos del procedimiento.

En este sentido, se han logrado avances en la implementación de la transparencia en armonía con la publicidad de las actuaciones, concretamente en lo relativo a la adecuación de la contratación pública a través de medios electrónicos (SECOP), ${ }^{8}$ para articular la información y publicación de las actuaciones públicas al servicio de las entidades mismas y de los ciudadanos, logrando así hacerlos partícipes en el proceso (artículo 3 de la Ley de Colombia 1.150 de 2007).

Bajo los anteriores supuestos, se podría indicar que la concreción de la participación ciudadana se determina en su intervención durante las diferentes etapas del proceso, puesto que, como lo reza la norma, «todo contrato que celebren las entidades estatales estará sujeto a la vigilancia y control ciudadano» (artículo 66 de la Ley de Colombia 80 de 1993).

De esta manera, en un primer momento, es decir, en la etapa de planeación, los ciudadanos pueden, como interesados, «hacer comentarios al proyecto de pliego de condiciones a partir de la fecha de publicación de los mismos» (artículo 2.2.1.1.2.1.4 del Decreto de Colombia 1.082-2015).Y su intervención, puede tener fundamento en la convocatoria a las veedurías ciudadanas a través del acto administrativo general de apertura al proceso de selección (artículo 2.2.1.1.2.1.5 del Decreto de Colombia 1.082-2015).

Sin embargo, en lo tocante a los comentarios al proyecto de pliego, la norma especial no determina la obligación concreta de dar respuesta a tales observaciones, lo que hace necesario acudir a las reglas generales del procedimiento administrativo.

Por otro lado, en lo que se refiere al proceso de contratación por licitación, existen dos audiencias públicas obligatorias: la audiencia de asignación de riesgos y la de adjudicación del contrato.

7. La consagración del principio de transparencia tiene origen en la Ley 80 de 1993 en su artículo 24, asimismo, en la Ley 1.150 de 2007, por medio del cual se introducen medidas para la eficiencia y la transparencia en la contratación. En ese sentido también, el Decreto 1.082 de 2015, por medio del cual se expide el decreto único reglamentario del sector administrativo de la planeación. Por otro lado, la Ley 1.474 de 2011 conocida como el «Estatuto Anticorrupción». Además de estos, diferentes leyes, decretos que evocan la transparencia en las actuaciones del Estado, particularmente tratándose de la contratación pública.

8. El SECOP (Sistema Electrónico de Contratación Pública) es un instrumento de apoyo a la gestión contractual de las entidades estatales, que permite la interacción de las entidades contratantes, los proponentes, los contratistas, la comunidad y los órganos de control, materializando la transparencia y la publicidad. Reglamentado a través del Decreto 2.485 de 2011, es manejado por «Colombia Compra Eficiente», entidad administrativa encargada del manejo de las compras públicas. 
Respecto de la primera, la norma indica que la entidad deberá presentar el análisis de riesgo efectuado y proceder a hacer la asignación de los mismos. De la misma manera, en la misma audiencia, procede a solicitud de un interesado, si es necesario, una precisión sobre el alcance y contenido de los pliegos de condiciones. En la segunda, se otorga la palabra a los oferentes o a quienes éstos autoricen (artículo 23 del Decreto de Colombia 1.510-2013).

Frente a esta situación surge una pregunta: debido al carácter público de las audiencias de licitación y a los límites a la participación en razón de la naturaleza del objeto (Dávila, 2016: 424), ¿la intervención ciudadana se predica únicamente respecto de las partes interesadas directamente en el contrato (Estado-oferentes) o también de aquellos cuyos efectos contractuales de manera relativa les afecta (ciudadanos)?

Una lectura superficial de la norma, entendería que, con relación a la audiencia de adjudicación, si el precepto consagra expresiones como «en la audiencia los oferentes pueden pronunciarse», «la entidad debe conceder el uso de la palabra por única vez al oferente», «toda intervención debe ser hecha por la persona o las personas previamente designadas por el oferente», diríamos que se predica respecto de la entidad pública contratante y los oferentes, por cuanto no hace referencia expresa a otros sujetos. Es más, lo más amplio que consagra la norma es que «terminadas las intervenciones de los asistentes a la audiencia, se procederá a tomar la decisión».

Sin embargo, a pesar de lo anterior, también podrán participar las organizaciones de veeduría ciudadana y cualquier persona que así lo desee, quienes verificarán que las deliberaciones y decisiones adoptadas en ella y consignadas en el acta, correspondan con el pliego y sus términos. ${ }^{9}$

Por otro lado, con relación a la contratación estatal por concurso de méritos, la legislación indica que luego de recibir las manifestaciones de interés y los documentos que acrediten la idoneidad de los oferentes, la entidad debe adelantar una precalificación a través de un informe donde los interesados puedan hacer comentarios al mismo en los términos previstos (artículo 2.2.1.2.1.3.5 del Decreto de Colombia 1.0822015). Tal intervención, a nuestro juicio, deberá entenderse en un sentido amplio, es decir, no solo respecto de los oferentes.

Con todo, es necesario precisar que la intervención de los ciudadanos como partícipes de la contratación pública varía de acuerdo con el interés, el objeto, la calidad y los efectos del contrato mismo. Por ejemplo, no es lo mismo el interés que se tenga en un proceso mediante el cual se contrate el suministro de materiales de impresión, que un contrato adjudicado a un consorcio para construir troncales de transporte masivo en las vías más transitadas de la ciudad.

9. En ese sentido, la serie de documentos de consulta del Plan Nacional de Formación sobre el Control Social a la Contratación Estatal, elaborado entre otras entidades, por la Contraloría General de la República, la Veeduría Distrital de Bogotá, la Procuraduría General de la Nación, etcétera. Publicado en el 2006. 
Por otro lado, será importante distinguir la participación ciudadana entendida como los «terceros relativos» a los cuales les afectan o benefician los efectos de determinado contrato e intervienen en las formas y los términos legales de los ciudadanos interesados en hacer parte del contrato, puesto que tanto la ejecución del principio de transparencia como el de publicidad, se extiende en ambos sentidos.

Instrumentos de participación ciudadana en la lucha contra la corrupción: ¿efectivos o ilusorios?

La intervención de la sociedad civil en la esfera de lo público no se limita a los procesos electorales o de participación y representación política (Guillén, Sáenz y Badii, 2009: 179). Se refiere, en términos de Cunill a «la intervención de particulares en actividades públicas en tanto portadores de determinados intereses sociales» (1991: 56). Entendida y adecuada a nuestro caso, como la participación ciudadana en el plano de la gestión pública y no en el estrictamente político (Ferrero y Hoehn, 2014: 15-16).

Lo que supone que dicha intervención está vinculada directamente a la producción de bienes y servicios por parte de la administración pública y las actividades que se derivan de este proceso. Bien sea a través de la participación consultiva, resolutiva, fiscalizadora y de ser posible, en la ejecución (Ferrero y Hoehn, 2014: 15-16).

En ese sentido, el ordenamiento jurídico colombiano en materia del derecho a la participación democrática tiene como objeto la promoción, protección y garantía de las diferentes modalidades de participación en la vida política, administrativa, económica, social y cultural (artículo 1 de la Ley de Colombia 1.757 de 2015)

En consecuencia, el reciente Estatuto de la Participación Ciudadana (Ley 1.757 de 2015) determina ciertos mecanismos a través de los cuales se pretende lograr el objeto trazado.

Entre los diferentes mecanismos que propone la ley en su artículo 4 encontramos los referendos, el cabildo abierto, las iniciativas legislativas o normativas, las consultas populares de origen ciudadano ${ }^{10}$ y las revocatorias de mandato, las cuales, a excepción del cabildo abierto, se rigen por unas reglas generales y comunes en aras de garantizar el orden y la transparencia, de cuya decisión se predica un obligatorio cumplimiento, si cumple con determinados requisitos, traducidos en proporcionalidad respecto de la población.

Por otro lado, y de gran importancia, el estatuto dedica un título especial a la rendición de cuentas en las ramas ejecutiva y legislativa del poder público, entendida como una «expresión del control social que comprende acciones de petición [...] y

10. Cabe destacar la iniciativa de consulta popular anticorrupción que lidera determinado sector político en Colombia, que pretende, a juicio de quienes la lideran, «domesticar la clase política y derrotar su corrupción». 
la evaluación de la gestión [...].» (artículo 48 de la Ley de Colombia 1.757 de 2015)"11, cuya finalidad se concreta en la búsqueda de la transparencia de la gestión de la administración pública para lograr la adopción de los principios de buen gobierno, eficiencia, eficacia, transparencia, etcétera (artículo 48 de la Ley de Colombia 1.757 de 2015).

Esta rendición obligatoria de cuentas se determina como una estrategia para realizar y generar espacios o encuentros que pueden ser presenciales o virtuales, con el objetivo de que los ciudadanos y las organizaciones sociales evalúen la gestión y los resultados, mínimo dos veces al año.

Asimismo, en concreción de la expresión del control social, la Ley, en su título V, resalta la característica de derecho y deber (entiéndase cargas bajo los postulados del capítulo «La prevención del daño como herramienta de combate contra la corrupción» del presente escrito) que tiene dicho control, cuyo ejercicio de seguimiento y evaluación puede darse de manera individual o a través de sus organizaciones.

En ese sentido, el control social puede realizarse a través de Veedurías Ciudadanas, Juntas de Vigilancia, Comités de Desarrollo y Control Social de los Servicios Públicos Domiciliarios, entre otros.

De esta manera, se proponen en términos generales herramientas para su ejercicio, entre ellas, la presentación de observaciones, peticiones, denuncias, quejas, acciones constitucionales, participación en audiencias públicas, etcétera (artículo 55 de la Ley de Colombia 1.757 de 2015).

Ahora bien, tratándose del combate contra la corrupción en las diferentes esferas del Estado, el contenido del Estatuto de Participación Ciudadana es viable, en tanto legitima la necesidad de tal intervención como instrumento o ayuda en la búsqueda de la transparencia.

Por consiguiente, frente a este flagelo, se han dado otras iniciativas en sede legislativa. Por ejemplo, el «Estatuto Anticorrupción», Ley 1.474 de 2011, mediante el cual se busca el fortalecimiento de los mecanismos de prevención para la efectividad de la gestión pública, que concretamente presenta diferentes medidas de participación ciudadana en el desarrollo de las etapas de la contratación por parte de las entidades administrativas.

Por otro lado, se expidió el Decreto 19 de 2012, llamado también «Decreto Antitrámites», a través del cual se promueve el desarrollo de los postulados del buen gobierno, en consonancia con la cercanía al ciudadano, mediante la eliminación de requisitos para acceder a los servicios de la administración.

Del mismo modo, la Ley 850 de 2003, por la cual se reglamenta las veedurías ciudadanas, concede facultad a los ciudadanos o a las diferentes organizaciones comunitarias para ejercer vigilancia sobre la gestión pública respecto a las autoridades de cualquier orden. En todo caso, los mecanismos propuestos no son diferentes a los que

11. La cursiva es nuestra. 
hasta ahora se han mencionado: intervención en audiencias, propuestas, denuncias, peticiones, etcétera.

Por su parte, la Política Pública Integral Anticorrupción, propuesta en el Conpes 167 de $2013{ }^{12}$ resalta la importancia de las «auditorías visibles» y los «procesos de rendición de cuentas en particular». Además, en aras de mejorar la información para el ejercicio del control social, implementa, entre otras herramientas, un plan de acción con énfasis en los municipios, articulado con las comisiones regionales de moralización y la Red Institucional de Apoyo a las Veedurías Ciudadanas, ambas conformadas por particulares al servicio de la comunidad.

En términos generales, se intenta hacer un planteamiento sobre la iniciativa legislativa en los principales mecanismos de participación ciudadana, más aún cuando se trata de combatir la corrupción. A simple vista la intención es válida, aun idealista. Sin embargo, la concreción real de la misma no se adecua a lo esperado; un ejemplo claro está en el Conpes 167 de 2013, respecto de la reducción de los recursos destinados por las entidades para el fortalecimiento del control social para la prevención de la corrupción, casi el $90 \%$ en el 2017 con relación a hace cuatro años.

Frente al pesimismo que engloba la efectividad de mecanismos de participación ciudadana en Colombia, más aún cuando se trata de combatir la corrupción, surge la iniciativa de distintas instituciones que se muestran a la vanguardia de la transparencia, ejemplo claro de esto, es la Estrategia de transparencia y rendición de cuentas del Consejo de Estado, con el objetivo de disminuir el número de procesos para que las personas puedan gozar de una justicia eficiente.

Por otro lado, el compromiso con el diseño de un Sistema de Alertas Tempranas (SAT) en corrupción y mala administración de la Procuraduría General de la Nación, compuesto por tres subsistemas (información, análisis y respuesta articulada institucional), permite, entre otras cosas, generar un reporte de alertas entre actores institucionales, gremiales y académicos frente a diferentes eventos de corrupción, principalmente en la contratación pública.

Asimismo, mediante el Decreto 1.674 de 2016, el Gobierno Nacional define las personas expuestas políticamente (PEP) y sus obligaciones con el sistema financiero para generar una cultura de transparencia en el sector público, las cuales son supervisadas por diferentes entidades del orden nacional, entre ellas, la Fiscalía General de la Nación.

Con lo anterior, se evidencia un sinnúmero de mecanismos generales o particulares frente al combate contra la corrupción en el orden jurídico colombiano, siendo notoria una voluntad por generar una cultura de transparencia, algunos ya con re-

12. El Conpes, Consejo Nacional de Política Económica y Social, es la máxima autoridad nacional de planeación y se desempeña como organismo asesor del Gobierno en todos los aspectos relacionados con el desarrollo económico y social del país. 
sultados manifiestos, otros con necesidad de tiempo y compromiso para demostrar su efectividad.

\section{Garantías a la participación ciudadana para la construcción de la transparencia}

La finalidad esencial del Estado de facilitar, promover y garantizar la participación de todos los ciudadanos en las decisiones que los afectan, en la vida económica, política, administrativa y cultural de la nación, es un mandato constitucional.

Es decir, por la posición de garante que tiene el Estado, surgen deberes estatales genuinos (Perdomo, 2001: 87) de carácter especial, positivo y prestacional a favor de los ciudadanos como respuesta a los principios básicos constitucionales.

Por esta razón, desde la misma ley de organización y funcionamiento de las entidades del orden nacional hasta en el Estatuto anticorrupción, se ha instituido un capítulo dedicado a la «democratización y control social de la Administración Pública» (capítulo VIII de la Ley de Colombia 489 de 1998), a través del cual se determina la obligación de todas las entidades y organismos de desarrollar su gestión acorde con los principios de democracia participativa.

En ese sentido, además de los instrumentos de participación ciudadana planteados en el punto anterior, la ley propone su incorporación a los planes de desarrollo y de gestión. Por otro lado, determina la importancia de generar incentivos y apoyo a la formación de asociaciones y mecanismos de asociación, en representación de los usuarios y los ciudadanos.

En concordancia con lo anterior, el ya citado Estatuto de Participación Ciudadana, en su artículo 94, consagra el «gasto en participación ciudadana» como el financiamiento de las actividades y proyectos para la promoción, protección y garantía al ejercicio del derecho de participación. Tales recursos pueden tener fuente en la actividad fiscal del Estado y en la cooperación internacional.

Del mismo modo, el estatuto crea los «incentivos simbólicos a la participación ciudadana», como mecanismos para el fortalecimiento y motivación de la población a intervenir en las decisiones públicas.

Aunado a lo presentado sobre garantías generales a la participación ciudadana, el Plan Nacional de Desarrollo (2014-2018) en el rubro correspondiente a la implementación de la política pública anticorrupción, plantea, entre otras cosas, una medición de la efectividad de los mecanismos de participación en la reducción de la corrupción y en la capacidad de respuesta a los ciudadanos, que significaría «avanzar hacia un modelo de control y vigilancia focalizada más en los resultados que en las sanciones» (Plan Nacional de Desarrollo, Ley de Colombia 1753 de 2015).

Por otra parte, además de las garantías al debido proceso que se deben surtir en todas las actuaciones administrativas y judiciales, cuando los ciudadanos accedan a través de los requerimientos, denuncias y peticiones, particularmente si se trata de 
delatar actos de corrupción, se debe brindar protección y, dependiendo la situación, confidencialidad.

Además, es necesario fortalecer los mecanismos de incentivos, los cuales motivarían a los ciudadanos a colaborar con las autoridades delatando actos de corrupción de los cuales tengan conocimiento, bien sea de manera directa o a través de las organizaciones que se han instituido.

Tratando de brindar soluciones a lo anterior, actualmente cursan en el Congreso proyectos de ley de iniciativa gubernamental con el objetivo de generar medidas de protección y reparación para quienes denuncien actos de corrupción, regular el ejercicio de cabildeo para asegurar la igualdad a la hora de adoptar decisiones, prohibición de aceptar invitaciones y dádivas por parte de personas que tengan un interés directo o no en la gestión pública, etcétera.

De alguna u otra manera, es necesario actuar frente a la lucha cooperada contra la corrupción, donde el Estado y los ciudadanos sean miembros activos de las iniciativas, arquitectos de las propuestas y destinatarios de los beneficios, los cuales contribuirían, entre otros factores, a la disminución de la pobreza y la garantía de la igualdad y la transparencia.

\section{Consideraciones finales}

La corrupción es un problema que se presenta, entre otras cosas, como fuente de gran parte de la desigualdad que agobia los pueblos; en el caso particular, el Estado colombiano, ya que transgrede el adecuado andamiaje de las instituciones que fungen como escenarios para el diseño, la construcción y la ejecución de las políticas públicas tendientes a lograr el desarrollo económico y social. En este sentido, uno de los focos a través del cual se gesta, o simplemente, tiende a tomar expansión la corrupción, es la contratación estatal.

Por esta razón, frente a la necesidad de establecer mecanismos para contrarrestar sus nefastos efectos, la prevención del daño antijurídico toma amplia relevancia, puesto que aun siendo una figura propia del derecho privado antiguo (aún en vigencia), permite entender la dinámica de los actores que participan en una relación contractual, donde se atribuye al perjudicado la carga de evitar o mitigar el daño.

De ahí, la población civil cumple un papel importante, por cuanto sin ser parte directamente en la celebración del contrato estatal, se presentan como terceros relativos, a quienes los efectos del mismo pueden llegar a perjudicarles.

De esta manera resulta apropiada la figura, en la medida en que involucra en las actividades y decisiones públicas a los ciudadanos, brindando legitimidad a las mismas y proyectando el elemento democrático como uno de los pilares del Derecho Administrativo contemporáneo.

Es más, corresponde a la materialización de los principios de «democracia delibe- 
rativa», mediante la cual «la actividad permanente de construcción de Estado parece encontrar en la formulación de Habermas los presupuestos éticos-políticos más plausibles para la actuación correcta de la ciudadanía respecto a dicha actividad: ciudadanos con alto grado de participación política en la construcción de unidad política, de deliberación pública regulada por el respeto a los principios constitucionales, y el seguimiento de los procedimientos institucionalizados de comunicación» (Domínguez, 2013: 325).

Así, se permite determinar que los ciudadanos, en tanto son perjudicados por la indebida celebración y/o ejecución de los contratos que adelante el Estado, tienen cargas, las cuales invitan a los mismos a realizar actuaciones en su propio beneficio, por ejemplo, ayudar a preservar y garantizar el adecuado desarrollo de los fines del Estado.

Estas cargas tienen origen en la misma constitución y se presentan como deberes genéricos positivos, sin embargo, a nuestro juicio, el entendimiento adecuado que se les debe dar es de simplemente «cargas», por cuanto un deber es un elemento estructural de una obligación.

En ese entendido, si por alguna razón se desatienden dichas cargas, no generan una obligación de resarcimiento, por cuanto son solo una invitación. Es decir, si los ciudadanos omitieron ejercer determinado control frente a una situación que de alguna u otra manera genera corrupción, no pueden ser sujetos de responsabilidad civil, así se generen indeseados perjuicios.

Es por esto que es necesario un empoderamiento de la población civil para que, de manera activa y cooperativa, participe en el escenario público, particularmente en los eventos donde se vean involucrados en gran manera sus intereses sociales.

Este objetivo, de alguna u otra manera, lo ha entendido el ordenamiento jurídico colombiano, pues ha dispuesto un armazón legislativo en aras de lograr una adecuada participación ciudadana en diferentes eventos, tales como la contratación pública.

Sin embargo, a nuestro juicio, las garantías otorgadas por el Estado para el cabal y adecuado desarrollo del objetivo requieren mayor fortalecimiento, en términos de incentivo, reconocimiento y protección.

\section{Referencias}

Abmann Schmidt, Eberhard (2014). «El concepto de la constitucionalización del Derecho administrativo». En Alberto Montaña Plata y Andrés Fernando Ospina Garzón (coords). La constitucionalización del Derecho Administrativo I: XV Jornadas Internacionales del Derecho Administrativo. Bogotá: Universidad Externado de Colombia.

AGA, Alianza Gobierno Abierto (2017). Colombia, hacia un Estado abierto: Tercer plan de acción nacional 2017-2019. 
BERMúdez Soto, Jorge (2005). «El principio de confianza legítima en la actuación de la administración como límite a la potestad invalidatoria». Disponible en http:// bit.ly/2kSBuRN.

Bianca, C. Massimo (2007). Derecho civil: el contrato. 2. ${ }^{a}$ edición. Bogotá: Universidad Externado de Colombia.

Chevallier, Jacques (2011). El Estado posmoderno. Bogotá: Universidad Externado de Colombia.

CorTÉs, Édgar (2006). «Constitución y responsabilidad civil. Una relación ambivalente». Revista de derecho privado 11: 171-179. Bogotá.

-. (2009). Responsabilidad civil y daños a la persona: El daño a la salud en la experiencia italiana ¿un modelo para América Latina? Bogotá: Universidad Externado de Colombia.

Cunill Grau, Nuria (1991). Participación ciudadana. Caracas: CLAD.

DABIN, Jean (2003). Doctrina general del Estado: Elementos de filosofía política. México D.F.: Universidad Nacional Autónoma de México.

Dávila Vinueza, Luis Guillermo (2016). «Antecedentes de la Ley 8o de 1993 y posteriores modificaciones». En Régimen jurídico de la contratación estatal. $3 .{ }^{a}$ edición. Bogotá: Legis.

De Cupis, Adriano (1970). «Naturaleza de los efectos jurídicos del daño: la prevención del daño». 2. ${ }^{a}$ edición. En El daño. Barcelona: Bosch.

Diéz-Picaso, Luis (1979). La representación en el derecho privado. Madrid: Civitas.

Domínguez, Héctor (2013). «Democracia deliberativa en Jürgen Habermas». Analecta Política 5: 301-326.

EsNer, Albin (2000). «La nueva evolución del Derecho Penal Económico». Revista de derecho penal, pp. 41-56. Disponible en http://bit.ly/2oZYVoR.

Ferrero, Mariano y Marek Hoenn (2014). «Participación ciudadana: un marco teórico», pp. 15-16. Disponible en http://bit.ly/2p2lhPu.

García de Enterría, Eduardo y Tomás-Ramón Fernández (2005). Curso de derecho administrativo. Tomo 2. 14. ${ }^{\mathrm{a}}$ edición. Madrid: Thomson Reuters - Civitas.

García Villegas, Mauricio y Javier Revelo Rebolledo (2010). Estado alterado: clientelismo, mafias y debilidad institucional en Colombia. Bogotá: Dejusticia.

Gordillo, Agustín (2014). Tratado de Derecho Administrativo y obras selectas. Tomo 2: la defensa del usuario y del administrado. Buenos Aires: Fundación de Derecho Administrativo.

Guillén, Amalia, Karla Sáenz, Mohammad Badir y Jorge Castillo (2009). «Origen, espacio y niveles de participación ciudadana». Daena 9(1): 179-193. México. Disponible en: http://www.cesem.org.mx/web2/images/escmun/df/guillen.pdf

Henao Pérez, Juan Carlos (2015). «Las formas de reparación en la responsabilidad del estado: hacia su unificación sustancial en todas las acciones contra el Estado». Revista de Derecho Privado 28: 277-366. Bogotá. 
Hinestrosa, Fernando (2008). La representación. Bogotá: Universidad Externado de Colombia.

-. (2015). Tratado de las obligaciones II: De las fuentes de las obligaciones: el negocio jurídico. Volumen 1. Bogotá: Universidad Externado de Colombia.

Hоввеs, Thomas (1987). Leviatán o la materia, forma y poder de una república, eclesiástica y civil. México D.F.: Fondo de Cultura Económica.

Matallana Camacho, Ernesto (2013). Manual de la contratación de la administración pública. 3. ${ }^{a}$ edición. Bogotá: Universidad Externado de Colombia.

Ospina Fernández, Guillermo y Eduardo Ospina Acosta (2014). Teoría general del contrato y del negocio jurídico. 7. ${ }^{a}$ edición. Bogotá: Temis.

Perdomo Torres, Jorge Fernando (2001). La problemática de la posición de garante en los delitos de comisión por omisión. Bogotá: Universidad Externado de Colombia.

Pimiento Echeverri, Julián Andrés (2015). Derecho Administrativo de Bienes: los bienes públicos, clasificación, régimen jurídico. Bogotá: Universidad Externado de Colombia.

Rawls, John (2006). Teoría de la Justicia. 2. ${ }^{a}$ edición. Cambridge: The Belknap Press.

SAN Martín Neira, Lilian (2012). La carga del perjudicado de evitar o mitigar el daño: estudio histórico- comparado. Bogotá: Universidad Externado de Colombia.

SANTOS Rodríguez, Jorge (2016). «Democratización de la administración pública y fortalecimiento de la participación ciudadana: instrumentos para la paz desde el derecho administrativo». En Alberto Montaña Plata, Andrés Fernando Ospina Garzón (coords.) (2016). La constitucionalización del Derecho Administrativo II: el derecho administrativo para la paz. Bogotá: Universidad Externado de Colombia.

Secretaría de Transparencia, Secretaría de la República de Colombia (2013). Documento Conpes núm. 167. Disponible en: http://bit.ly/2wc522a.

Wunder Hachem, Daniel (2011). Principio constitucional da supremacía do interesse público. Belo Horizonte: Fórum.

\section{Agradecimientos}

El autor agradece a Édgar Cortés Moncayo por su incondicional apoyo y sus pertinentes consejos.

\section{Sobre el autor}

William Iván Gallo Aponte es estudiante investigador de último año de Derecho en la Universidad Externado de Colombia. Miembro fundador de la Red Iberoamericana Juvenil de Derecho Administrativo (con sede en la Ciudad de México). Sus correos electrónicos son williamg.aponte@gmail.com y william.gallo@est.uexternado. edu.co. 
La Revista de Derecho Público es publicada, desde 1963, dos veces al año por el Departamento de Derecho Público de la Facultad de Derecho de la Universidad de Chile. Su propósito es la difusión de los avances del derecho público nacional e internacional y la socialización de artículos de investigación inéditos tanto de la comunidad académicas nacional e internacional.

DIRECTORA

Ana María García Barzelatto

SECRETARIO DE REDACCIÓN

Felipe Peroti Díaz

(fperoti@derecho.uchile.cl)

SITIO WEB

revistaderechopublico.uchile.cl

CORREO ELECTRÓNICO

publico@derecho.uchile.cl

LICENCIA DE ESTE ARTÍCULO

Creative Commons Atribución Compartir Igual 4.0 Internacional

La edición de textos, el diseño editorial

y la conversión a formatos electrónicos de este artículo

estuvieron a cargo de Tipográfica

(www.tipografica.cl). 